\title{
PEER MENTORING: ENHANCING ECONOMICS FIRST YEARS' ACADEMIC PERFORMANCE
}

\author{
K. M. Dos Reis* \\ e-mail: kdosreis@uwc.ac.za \\ D. $Y u^{*}$ \\ e-mail: dyu@uwc.ac.za \\ ${ }^{*}$ Faculty of Economics and Management Sciences \\ University of the Western Cape \\ Cape Town, South Africa
}

\section{ABSTRACT}

South African higher education institutions have been grappling with the high dropout rate, specifically at first year level. Despite universities' attempts to implement various strategies to increase student retention, there is very little or no empirical warrant to validate these attempts of research in the South African context. Hence, the aim of this study is to explore how disciplinespecific peer mentoring impacts first year students' academic performance. The two most significant findings of this study are that firstly, the mean continuous assessment mark of the mentees (73.6) is significantly higher compared to students who were not mentees and, secondly, the mentees' final examination performance was also higher (60.9 versus 52.9 ).

This study highlights the possibilities of using peer mentoring to improve first years' academic performance. The evidence as revealed in the study provides insights into these possibilities. For example, the peer mentees indicated that they the peer mentors weekly motivational messages inspired them to continue with their studies and the continuous support from the peer mentors assisted them to understand the difficult concepts of Economics. While this study did not focus on the peer mentors, we also found that they were willing to participate voluntarily in this programme, as they believed that there are multiple benefits to being a peer mentor. We argue that the implementation of discipline-specific peer mentoring programmes across all disciplines could facilitate student retention and increase the overall pass rate of first year students.

Keywords: peer mentoring, mentor, mentee, first year experience, Higher Education

\section{INTRODUCTION}

Currently the Bachelor of Commerce (BCom) programme in the Economics and Management Sciences faculty at a university in the Western Cape experiences high attrition rates in the first year Economics module. This is the largest faculty in the university and approximately five 
thousand students are registered for BCom and Bachelor of Administration (BAdmin) programmes combined. An overwhelming majority of students are classified as black and coloured.

At first year level, approximately three hundred students register for the ECO133 module but the pass rate is between 45 per cent and 55 per cent. In fact this module is considered an "at risk module" due to the low pass rate. This is a cause for concern for the faculty as this low pass rate also impacts on throughput rates. To increase the pass rate, a pilot study was conducted to explore how peer mentoring impacts Economics students' academic performance. The lecturer provided third year students with two assignments to choose from, one being the opportunity to participate in a peer mentoring programme. Hence this assignment formed part of the Economics curriculum and peer mentors were not remunerated for this activity. In fact, given that the university where the study was carried out has minimal resources, remunerating these students was not an option. It is interesting to note that an overwhelming majority of the third year Economics students signed up to be mentors. Monthly meetings were held with the mentors by a lecturer and faculty Teaching and Learning Specialist to gain insights into the mentors' challenges with the aim to provide guidance and appropriate strategies to overcome these challenges. The ECO133 students were invited to participate in the mentoring programme on a voluntary basis.

In this study we explore the possibilities of discipline specific peer mentoring as a catalyst to enhance first year students' academic performance. Given the austerity measures that South African universities are currently facing, we argue that peer mentoring embedded in a curriculum can assist universities to retain students particularly at first year level. Furthermore, peer mentoring also has the potential to give both mentor and mentee the opportunity to develop "soft skills" such as teamwork, motivation, decision making and positivity. The aim of this study is to explore how discipline-specific peer mentoring impacts first year students' academic performance and how the mentees responded to the peer mentors' assistance.

\section{LITERATURE REVIEW}

Peer mentoring is considered to be an alternative to the traditional concept of mentorship (Kram and Isabella 1985). While traditional mentoring is defined as an older, more experienced person mentoring a younger individual, peer mentoring matches mentors and mentees who are generally equal in age, experience, and power to provide guidance and social support (Angelique, Kyle and Taylor 2002, 196). Although peer mentors will show greater experience and achievement than their peers, the difference in experience and achievement levels are usually less evident. Peer-mentoring in the context of academia is defined as a relationship 
between two or more students whereby one student, who is to some extent more experienced, takes on a mentoring role to provide support and guidance to a less-experienced student (Crisp and Cruz 2009, 531). Hence, mentoring is considered as an approach to empower and liberate mentees (Hamilton 2003, 115). Furthermore, mentoring is also viewed to develop mentees to their full potential.

Falchikov (2001) notes that peer mentoring focuses on a more experienced student helping a less experienced one improve overall academic performance. According to McLean (2004, 182) student mentees look for senior students in whom they can confide because they feel that senior students are better able to "provide valuable advice in terms of how to work through issues and whom to consult regarding more serious concerns". This study points to the link between programme of study and the mentee's perception of the mentor as a reliable source of advice. Findings by Mee-Lee and Bush (2003) suggest that subject-specific knowledge is related to mentor credibility, with mentees generally looking for mentors with a good grasp of an academic subject. According to these researchers, sharing the same programme of study leads mentees to attribute greater credibility to their mentor. The nature of mentoring requires mentors to be suitably positioned to assist another student and is only feasible when the mentors themselves have some working knowledge of how to navigate the university environment (Terrion and Leonard 2007). Without such experience, a mentor's ability to play his or her role as peer mentor will be compromised. It is therefore important that student peer mentors have gained a certain level of experience of the university's environment, which is acquired through successful completion of at least a portion of their university studies (Terrion and Leonard 2007). While literature advocates what peer mentors' roles should be, Hamilton $(2003,108)$ stresses the importance of mentors displaying a "genuine interest" in their mentees. In addition to this sentiment, Allan $(2007,19)$ argues that mentors should be chosen based on the personal qualities and should possess the desire and ability to share their knowledge and skills.

The benefits of peer mentoring for universities are numerous as reported in the literature. These benefits include an increase in students' engagement in student activities offered by the university as a form of student volunteering (Clark, Andrews and Gorman 2013), an increase in retention and a decrease in attrition (Fox and Stevenson 2006) and improved satisfaction with the university experience and quality of education received, which could lead to increased commitment to the university (Clark et al. 2013; Higgins 2004). Other benefits reported are that both mentors and mentees "engage with learning material to such an extent that it promotes deep learning" which leads to an augmented understanding of content knowledge (Du Preez, Steenkamp and Baard 2013). Although peer mentoring could mainly be beneficial for first year students, mentors also benefit as demonstrated by Hall and Jaugietis $(2011,48)$. In their study, 
mentors revealed that their social, communication, employment and organizational skills improved. Concurring with this finding is $\operatorname{Keup}(2016,40)$ whose study revealed that peer mentors felt that their interpersonal skills were "much stronger", a greater sense of belong and also developed a better understanding of students from diverse backgrounds. In addition to this, they also reported that they would recommend the experience of being a peer mentor to other students.

A further review of literature showed that discipline-specific peer mentoring is most prevalent in Nursing, Accounting and Engineering (Higgins 2004; Fox and Stevenson 2006; Kieran and O'Neill 2009; Du Preez, Steenkamp and Baard 2013). Interestingly, all these studies share a common objective and that is to increase student retention and enhance academic performance. Although there is a common objective shared in these studies, we only found evidence in the empirical results of Fox and Stevenson's $(2006,189)$ study which found that mentoring does have a positive effect on the mentees' academic performance, while the other studies focussed mainly on developing strategies for peer mentoring programmes and investigating student experiences. These objectives are supported by Terrion and Leonard (2007) who state that the implementation of structured peer mentoring programmes will decrease student attrition and improve student success for both mentor and mentee.

Almost a decade ago Crisp and Cruz (2009) did a critical review of the literature on mentoring programmes in higher education between 1990 and 2007. After an extensive review they found that mentor programme development is not sufficiently keeping pace with the theoretical or empirical research on the concept of mentoring within higher education. While these authors made several recommendations for further research, we align our study with their recommendation to research the impact of various mentoring activities on students' success (Crisp and Cruz 2009, 541).

In South Africa a study was conducted by Du Preez, Steenkamp and Baard (2013) to explore the experiences of mentors and mentees in a peer mentoring programme in the Faculty of Economics and Management Sciences (EMS). In addition to this, they also explored the possibility of this programme to facilitate student success in the faculty. Evidence of their study revealed that the main reasons for mentees participating in the programme were to improve their marks as they were struggling with the module and given that certain mentees are second language English speakers, they indicated that mentors could explain concepts in their mother tongue (Du Preez, Steenkamp and Baard 2013, 1230).

Hall and Zarni Jaugietis (2010) identified the "Academic and Social Integration" approach (Tinto 1993; 1995) as most suitable for peer mentoring programmes that centre on engagement rather than instruction. Integration refers to the extent to which students identify with the 
university community and with the department in which they are registered. Social support refers to the creation of social networks among students and emotional support from peers and staff.

Tinto's Student Integration Model $(1993,1995)$ was chosen as the overarching framework for this study due to its particular theoretical underpinning and the significant volume of work Tinto put into explicating his theory. Tinto's integration model places a strong emphasis on the role of "within-institution" peer culture. Tinto (1995) found that students involved in community and collaborative learning programmes, where students learn from their peers, were involved in a wider range of learning activities, learned more and persisted at a higher rate than did similar students in more traditional learning settings. In being part of such shared learning experiences, the students found academic and social support for their learning among their peers and they became more actively engaged in their learning. In a more recent study Tinto (2009) made a profound statement that universities invest large amounts of funding to increase student retention rates, particularly at first year level, but he stressed that these institutions deal with this important issue like any other challenges universities are facing. Furthermore, he made the following statement:

"It is regrettable that too many universities still use such add-on programs as a 'vaccine' to treat the threat of freshman attrition. By leaving them at the margins of institutional life, by treating their ideas as add-ons to the real business of the university, institutions implicitly assume that they can 'cure' attrition by 'inoculating' students with a dose of educational assistance and do so without changing the rest of the curriculum and the ways students experience that curriculum."

Although more recent theoretical frameworks have been developed (Kirkham and Ringelstein 2008), these have referred specifically to peer assisted instruction rather than peer mentoring. While peer assisted instruction is beneficial for students (Arendale 2007), it tends to be more appropriate for tutoring a specific subject content knowledge (Kieran and O’Neill 2009).

Our research focuses on the relationship between student integration and retention as conceptualised by Tinto $(1993,1995)$. Hence, we explored how the peer mentors support through weekly motivational message and face to face meetings with their mentees influenced their academic performance. Moreover, Tinto's framework gave insights into the importance and relevance of peer mentoring as a tool to establish a "within-institution" peer culture.

\section{CONTEXT OF STUDY}

\section{First-year Economics modules at UWC}

The Department of Economics of the EMS Faculty offers two first year, semester modules, 
namely ECO133 and ECO134 (offered in the first and second semesters respectively). These modules (Principles of Economics) have exactly the same content, covering the core Microeconomics and Macroeconomics theories. ECO133 primarily serves students from BCom 4-year full-time and part-time programmes, and ECO134 is for students from various 3-year full-time programmes. In the case of ECO133, all students are eligible to write the final examination, and the final mark is calculated as: $0.5 \times \mathrm{CAM}+0.5 \times$ examination mark.

\section{Peer mentoring programme}

The peer mentoring programme has the following objective: to promote Economics education in the ECO133 module so as to encourage students to major in the subject and to increase the pass rate of the module.

During the first three weeks of the first semester, both ECO133 Principles of Economics and ECO311 third-year Econometrics students were informed about the mentoring programme and encouraged to register as mentees or mentors. At the end, 36 and 12 students registered as mentees and mentors respectively. In the fourth week, each mentor was allocated to three or four mentees. A meet-and-greet session took place between them at the start of the programme in the fifth week.

Mentors were asked to conduct the following activities during the semester: (1) attend a training workshop which addressed the expected roles of mentors and mentees, mentoring in the context of Higher Education, and an overview of the mentoring relationship; (2) create a WhatsApp group or Google Hangout (evidence of conversations) ${ }^{1}$; (3) send weekly motivational messages to mentees; (4) attend a 30-minute group meeting with mentees each week. Individual meetings with mentees could also be arranged; and (5) compulsory attendance of quarterly mentoring meetings. Each mentor received a certificate of merit at the beginning of June upon successfully fulfilling their designated roles.

It was important to provide peer mentors with a structure of how they should fulfil their role expectations to ensure that the mentees are given the type of support required to improve their overall academic performance. Hence, creating a Whatsapp group and having weekly meetings with the mentees would give both mentor and mentee the opportunity to establish a mentoring relationship that could lead to the support required by the mentee. To monitor the expectations of particularly the mentor, we hosted monthly meetings with them to obtain feedback of their overall experiences and they were required to submit a detailed report of their interactions with each mentee. The submission of this report, made them eligible for a mark and certificate.

To orientate the mentees regarding their role expectations, the faculty Teaching and 
Learning Specialist scheduled to meet with the first-years in their respective lecturing venues to discuss the role of mentees and to motivate them to enrol the program. In addition to this, a meet and greet session was arranged between the mentor and mentee. In this session, additional information regarding the programme was provided.

\section{Characteristics and academic performance of the mentees}

Data from the university's student administration system contained information on the demographic and school attainment characteristics of the students. Upon excluding the parttime students and full-time students who de-registered during the semester, the final ECO133 sample size was 267 students. The university's Marks Administration System (MAS) contained information on the ECO133 students' performance. Finally, although lecture and tutorial attendances are not compulsory, the latter attendance (there are eight tutorials in total) accounts for 8 per cent of the CAM.

\section{Methodology}

The methodology employed for the study is the education production function approach. Siegfried and Fels $(1979,925)$ group the literature on teaching methods and techniques into a production function approach. This approach investigates how output (measured in terms of results achieved in examinations or student evaluation questionnaires) is explained by various inputs, ranging from students' human capital (measured in terms of university entrance scores or prior knowledge of economics), the faculty's human capital (the qualifications and experience of lecturers), to the university environment (which specifically looks at the impact of class size), students' efforts (such as class attendance and study time) and peer mentoring (the research question of this study).

Explanatory variables of the multivariate analysis in this study include the following: demographic characteristics of the students (such as gender, population group, age, home language), school attainment characteristics (such as whether the students did Economics, English Home Language and Mathematics in Matric, as well as total entry points), university characteristics (such as whether the student stayed at a university residence, degree program enrolled for, class attendance, and participation in the mentoring programme).

As far as the UWC entry points are concerned, they are derived by a weighted system of declining scale to award points for the symbol obtained in each subject. For English and Mathematics / Mathematical Literacy, 15 points are awarded for level-8 result (90-100\%), 13 points for level 7 (80-89\%), and so forth until 1 point is awarded for level 1 (20-29\%). With regard to Life Orientation, 3 points are awarded for levels 7 and 8, 2 points for levels 4-6 and 
1 point for levels $1-3$. For the remaining four subjects, 8 points are awarded for level 8,7 points for level 7, and so forth. Therefore, the maximum attainable entry points are $65(15 \times 2+3+8$ $\times 4)$. Finally, in the event of a student doing more than seven subjects, the entry points are derived by considering the results of English, Mathematics, Life Orientation and four other best-performing subjects.

Of the full sample of 267 students, since everyone is eligible to write the final examination (the students are eligible to write the supplementary examination if they were unable to write the final examination due to reasons such as illness), the results of the Ordinary Least Squares (OLS) regressions will be robust, not influenced by any sampling selection bias. One drawback is that eight students did not have a final mark because they were absent from both final and supplementary examinations.

\section{EMPIRICAL FINDINGS}

\section{Descriptive statistics}

Table 1 presents the profile of the ECO133 students by their mentoring programme participation status. About 60 per cent of the students were aged 20 years. With regard to gender, it is interesting to see a greater female share $(61.1 \%)$ in the case of mentees compared to 45.5 per cent for those who were not mentees. Half of the mentees were Africans, while the corresponding proportion is only about one-third for those who were not mentees. 47.2 per cent of the mentees spoke African languages at home, while this proportion is only 30.7 per cent for those who were not mentees. About 17 per cent of mentees stayed at university student residences (this proportion is only 8 per cent for students who were not mentees). As expected, the majority of the ECO133 students came from the BCom 4-year programme $(58.8 \%$ for the whole sample), but this proportion is extremely high for mentees (75.0\%). Whilst 44.2 per cent of the ECO133 students enrolled for ECO133/134 for the first time, this share is much higher for the mentees $(72.2 \%)$.

As far as the school attainment characteristics are concerned, 64 per cent, 81 per cent and 56 per cent of mentees enrolled for English Home Language, Mathematics and Economics in Matric respectively, whilst the corresponding proportions are 72 per cent, 79 per cent and only 26 per cent for students who were not mentees. The mentees on average obtained 39.3 entry points, nearly one point above the mean of those who were not mentees (38.4). Nonetheless, the mean difference is not statistically significant, that is, the two groups are highly similar in terms of their Matric academic performance, on average.

For the ECO133 class attendance and performance, Table 1 shows that mentees were associated with significantly higher tutorial attendance, with a mean attendance of 7.3, compared to 5.9 for those who were not mentees. Another encouraging finding is that the mean 
Table 1: Profile of the ECO133 students

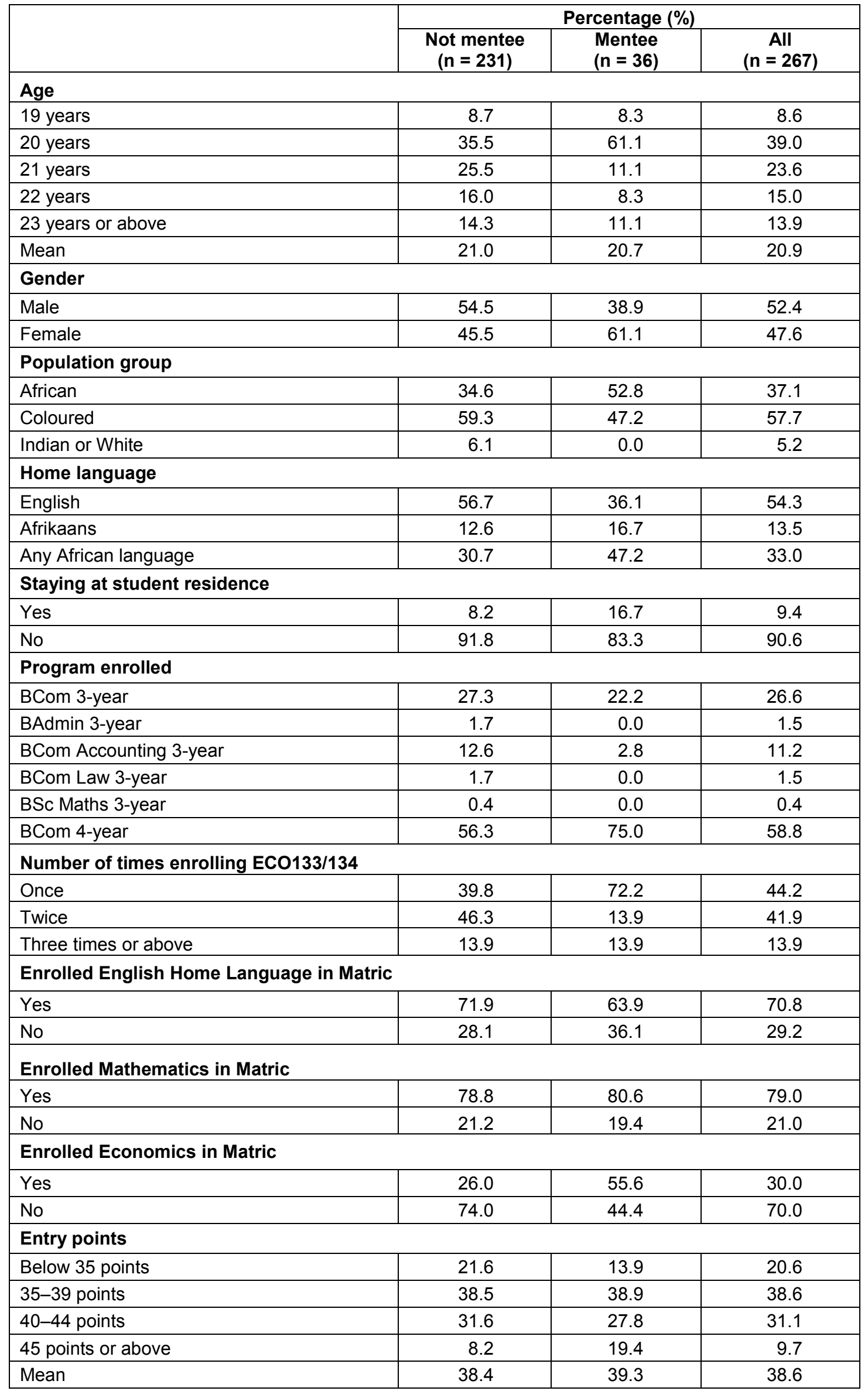




\begin{tabular}{|c|c|c|c|}
\hline \multicolumn{4}{|l|}{ Tutorial attendance } \\
\hline None & 1.3 & 0.0 & 1.1 \\
\hline Once or twice & 7.8 & 0.0 & 6.7 \\
\hline Three to four times & 12.1 & 5.6 & 11.2 \\
\hline Five to six times & 32.5 & 13.9 & 30.0 \\
\hline Seven times & 21.2 & 16.7 & 20.6 \\
\hline Eight times & 25.1 & 63.9 & 30.3 \\
\hline Mean & 5.9 & $7.3^{*}$ & 6.1 \\
\hline \multicolumn{4}{|l|}{ Year mark } \\
\hline Below 40 marks & 6.1 & 0.0 & 5.2 \\
\hline $40-49$ marks & 9.1 & 2.8 & 8.2 \\
\hline 50-59 marks & 16.0 & 5.6 & 14.6 \\
\hline 60-69 marks & 38.5 & 27.8 & 37.1 \\
\hline 70-74 marks & 12.6 & 16.7 & 13.1 \\
\hline $75-100$ marks & 17.7 & 47.2 & 21.7 \\
\hline Mean & 62.7 & 73.6 & 64.1 \\
\hline \multicolumn{4}{|l|}{ Final exam mark } \\
\hline Below 40 marks & 10.0 & 5.7 & 9.4 \\
\hline $40-49$ marks & 26.0 & 22.9 & 25.6 \\
\hline 50-59 marks & 37.0 & 20.0 & 34.6 \\
\hline 60-69 marks & 21.0 & 20.0 & 20.9 \\
\hline 70-74 marks & 3.2 & 8.6 & 3.9 \\
\hline $75-100$ marks & 2.7 & 22.9 & 5.5 \\
\hline Mean & 52.9 & $60.9^{*}$ & 54.0 \\
\hline \multicolumn{4}{|l|}{ Final mark } \\
\hline Fail: No final mark & 3.5 & 0.0 & 3.0 \\
\hline Fail: Below 50 marks & 11.7 & 5.6 & 10.8 \\
\hline Pass: $50-59$ marks & 37.2 & 19.4 & 34.8 \\
\hline Pass: $60-69$ marks & 35.1 & 33.3 & 34.8 \\
\hline Pass: $70-74$ marks & 8.2 & 13.9 & 9.0 \\
\hline Pass: $75-100$ marks & 4.3 & 27.8 & 7.5 \\
\hline Mean & 58.8 & $67.3^{*}$ & 60.0 \\
\hline Pass rate $(\%)$ & 84.8 & 94.4 & 86.1 \\
\hline
\end{tabular}

${ }^{*}$ The mean of mentees is statistically significant at alpha $=5 \%$, compared with the mean of students who are not mentees.

CAM of the mentees (73.6 marks) is significantly higher compared to that of students who were not mentees (62.7 marks). The mentees also enjoyed significantly higher final examination performance (60.9 marks versus 52.9 marks) and final marks (67.3 versus 58.8), compared to students who were not mentees. The kernel density curve in Figure 1 also confirms the same finding.

To conclude, the mentees are more likely to be African females aged 20 years, who did not enrol Economics in Matric but obtained 39 entry points on average; they attended tutorials more frequently and outperformed those who were not mentees by about 10 marks, in both the CAM and final mark.

\section{Multivariate analysis}

Table 2 presents the results of the multivariate econometric analysis on three dependent 
variables, namely CAM, final examination mark (254 students wrote this examination) and final mark (259 students had a final mark). As far as the regressions on the CAM are concerned, the Matric Mathematics dummy is the only statistically significant independent variable (with the expected positive sign) in regression [I] before the mentoring participation status and tutorial attendance are taken into consideration. In regression [II], both the Mathematics and mentee dummy variables are statistically significant. The latter result suggests that students who took part in the peer mentoring program, on average, obtained 10 marks higher in their CAMs compared to those who did not take part in the program.

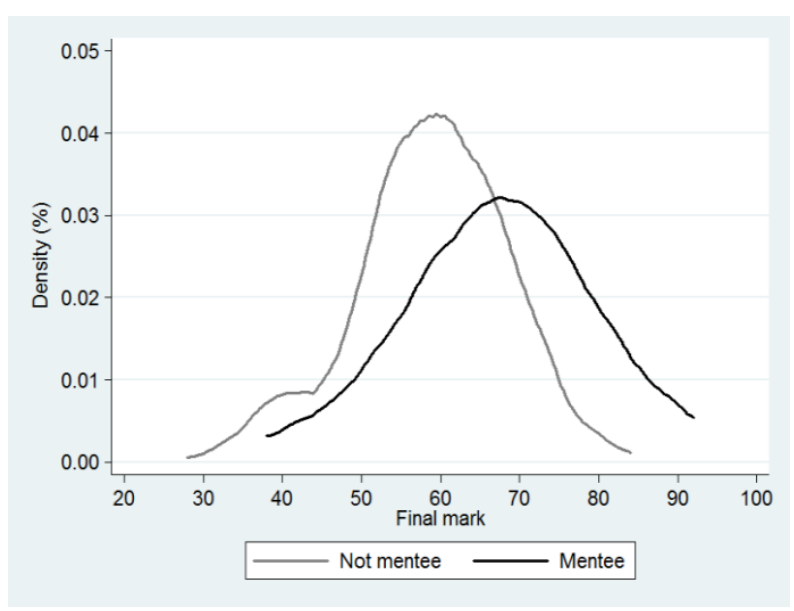

Figure 1: Density curves of final marks of ECO133 students

Table 2: Ordinary Least Squares (OLS) regressions on continuous assessment, final examination and final marks

\begin{tabular}{|c|c|c|c|c|c|c|c|c|c|}
\hline & \multicolumn{9}{|c|}{ Dependent variable } \\
\hline & \multicolumn{3}{|c|}{ CAM } & \multicolumn{3}{|c|}{ Final exam mark } & \multicolumn{3}{|c|}{ Final mark } \\
\hline & [l] & [II] & [III] & [IV] & [V] & {$[\mathrm{VI}]$} & [VII] & [VIII] & {$[\mathrm{IX}]$} \\
\hline $\begin{array}{l}\text { Dummy: Home } \\
\text { language being } \\
\text { English }\end{array}$ & -1.8479 & -1.7787 & 2.1078 & -2.5603 & -2.5410 & -0.7281 & -4.1309 & -4.0114 & -1.0808 \\
\hline $\begin{array}{l}\text { Dummy: Home } \\
\text { language being } \\
\text { Afrikaans }\end{array}$ & -2.7625 & -3.9088 & 2.3193 & 2.6464 & 1.7919 & 4.3006 & -1.6882 & -2.5182 & 1.4930 \\
\hline Dummy: Coloured & 2.7595 & 3.7084 & -1.9144 & 2.9318 & 3.6769 & 1.4955 & 3.9791 & $4.6461^{*}$ & 1.0093 \\
\hline $\begin{array}{l}\text { Dummy: Indian or } \\
\text { White }\end{array}$ & 3.9251 & 5.8442 & -4.7914 & 3.2947 & 4.6324 & 1.0099 & 3.6150 & 5.0271 & -0.8422 \\
\hline Dummy: Male & -1.6071 & -1.2164 & 1.4739 & 0.2512 & 0.3348 & 1.2322 & -0.6528 & -0.3839 & 1.1820 \\
\hline Age in years & -7.9737 & -3.0064 & 0.2757 & 6.8005 & 10.1122 & 10.8613 & 0.2317 & 3.8403 & 3.1300 \\
\hline Age in years squared & 0.1886 & 0.0779 & 0.0000 & -0.1679 & -0.2411 & -0.2610 & -0.0024 & -0.0831 & -0.0701 \\
\hline Entry points & 0.9283 & 1.7834 & -1.8744 & -0.0270 & 0.1120 & -1.3341 & 0.4616 & 1.0442 & -1.2287 \\
\hline Entry points squared & -0.0067 & -0.0178 & 0.0307 & 0.0102 & 0.0080 & 0.0268 & 0.0021 & -0.0055 & 0.0244 \\
\hline $\begin{array}{l}\text { Dummy: Matric } \\
\text { English Home } \\
\text { Language }\end{array}$ & 1.2195 & 0.4284 & -0.5423 & $4.2597^{*}$ & $3.7630^{*}$ & 3.2953 & $3.8804^{*}$ & 3.2217 & 2.2303 \\
\hline $\begin{array}{l}\text { Dummy: Matric } \\
\text { Mathematics }\end{array}$ & $4.7520^{* *}$ & $4.3792^{* *}$ & $4.9045^{* * *}$ & $9.1274^{* * *}$ & $8.8775^{* * *}$ & $8.8861^{* * *}$ & $7.4419^{* * *}$ & $7.1296^{\star \star \star}$ & $7.0370^{* * *}$ \\
\hline Dummy: Matric & 1.2445 & -0.3231 & -0.2750 & $2.7991^{*}$ & 1.7753 & 1.7622 & 2.0693 & 0.8950 & 0.6580 \\
\hline
\end{tabular}




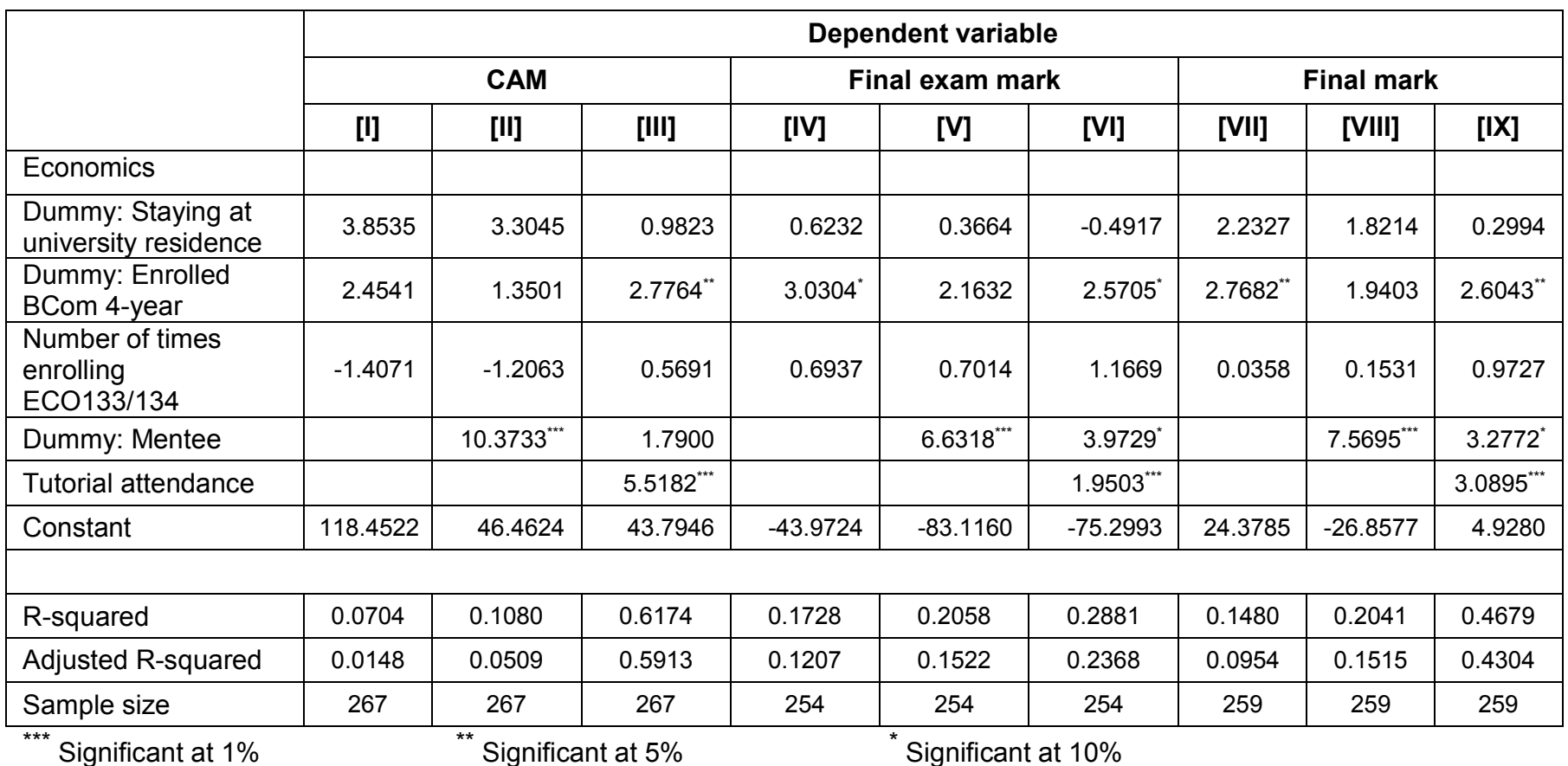

However, after adding controlling for tutorial attendance in regression [III], the mentee dummy is no longer significant (whilst the Mathematics dummy remains significant); it is rather the tutorial attendance frequency variable that is significant, with the coefficient suggesting that the student's CAM increases by 5.5 marks for each additional attendance. This result is not surprising at all, as it was previously mentioned that tutorial attendance accounts for 8 per cent of the CAM. Numerous past local studies also found that tutorial attendance has a positive significant impact on students' academic performance (e.g. Horn, Jansen and Yu 2011; Dlomo et al. 2011; Horn et al. 2011).

As far as the three regressions on the final examination mark are concerned, in regression [IV] the three Matric dummy variables (English, Mathematics and Economics) and the BCom 4-year program enrolment dummy are the only four statistically significant independent variables, with all of them having a positive sign. In regression [V], the mentee dummy is statistically significant with a coefficient of 6.6318 (meaning participation of the peer mentoring program is associated with significantly better examination performance), but the Matric Economics dummy becomes insignificant. In regression [VI] both the tutorial attendance and mentee dummy are significant with a positive sign, along with the Matric Mathematics and BCom 4-year programme dummy variables. However, the coefficient of the mentee variable (3.9729) is twice that of the tutorial attendance variable (1.9503), whereas the former variable is associated with a smaller and insignificant coefficient in regression [III]. Therefore, the results indicate that participation in the peer-mentoring program as mentees leads to a greater, significant impact on ECO133 examination performance. 
For the three regressions on students' final marks, once again the Matric Mathematics dummy is statistically significant in all regressions; the Matric English dummy is only significant in regression [VII] while the Matric Economics dummy is insignificant in all regressions. Furthermore, the BCom 4-year program dummy is significant only in regressions [VII] and [IX]. Finally, both the mentee dummy and tutorial attendance variables are significant with the expected positive sign in their coefficients in regression [IX], and the size of both coefficients is quite similar (slightly above three). To conclude, the results of the multivariate analysis suggest that participation in the peer mentoring program is associated with significant better academic performance in the ECO133 module.

Although this article focuses mainly on the first year's overall academic success, we would also like to highlight a brief qualitative analysis of the mentees' experiences in this study to emphasise how mentoring benefited them. As stated earlier in the article, all the participants were required to complete a survey that gave the mentor the opportunity to comment on their experiences with the mentee and vice versa was also expected from the mentor. The survey had a closed-ended and open-ended section. The closed-ended part gave the researchers an opportunity to gain insights of how mentors and mentees responded to each others' needs and the open-ended part gave the participants an opportunity to give feedback of their experience which might not necessarily be addressed in the closed-ended part. To maintain the focus of this article, we will only report on the mentees views of their mentors and overall experiences in the programme. Below is a table that illustrates the mentees views of their mentors:

Table 3: Results of mentee evaluation forms $(n=12)$

\begin{tabular}{|l|c|c|c|c|}
\hline & $\begin{array}{c}\text { \% Strongly } \\
\text { disagree }\end{array}$ & $\begin{array}{c}\text { \% } \\
\text { Disagree }\end{array}$ & \% Agree & $\begin{array}{c}\text { \% Strongly } \\
\text { agree }\end{array}$ \\
\hline [1]: Mentor was accessible and available & 0.0 & 8.3 & 66.7 & 25.0 \\
\hline [2]: Mentor communicated regularly & 0.0 & 0.0 & 75.0 & 25.0 \\
\hline [3]: Mentor assisted with academic queries & 8.3 & 0.0 & 83.3 & 8.3 \\
\hline [4]: Mentor provided regular motivation & 8.3 & 16.7 & 50.0 & 25.0 \\
\hline [5]: Mentor demonstrated reasonable concern & 0.0 & 8.3 & 75.0 & 16.7 \\
\hline [6]: Mentor showed professional attitude & 0.0 & 0.0 & 41.7 & 58.3 \\
\hline [7]: Learned important lesson(s) about life & 8.3 & 41.7 & 33.3 & 16.7 \\
\hline [8]: Learned important lesson(s) about career & 16.7 & 41.7 & 33.3 & 8.3 \\
\hline [9]: Receptive to mentor's advice & 0.0 & 0.0 & 83.3 & 16.7 \\
\hline [10]: Mentor was a beneficial asset & 0.0 & 16.7 & 58.3 & 25.0 \\
\hline $\begin{array}{l}\text { The three key highlights of Table 3 are as follows: } \\
\text { - 92\% of mentees agree that the mentors assisted with academic queries }\end{array}$ & & \\
• 75\% of mentees agree that the mentors provided regular motivation \\
• 83\% of mentees agree that the mentors were a benefit asset
\end{tabular}

The mentees and mentors responses were overwhelmingly positive, while only a few challenges were highlighted. It was interesting to note how the mentees valued support of their mentors in 
terms of facilitating their understanding of Economics. In this regard, one mentee iterated that his mentor is helpful with EC0133, while another mentee commented: "It benefits me a lot to understand the work and to put it into practice". One mentee felt that the program is "a useful tool in my life".

Certain mentees commented on how their mentors' motivations inspired them to stay focussed on their goal to be successful. Herewith their comments:

"My mentor is quite motivating, I receive daily inspirations from her and this keeps me going in life and at the university."

"According to this Peer Mentoring, it made me to know how important of passing your modules and working hard for achieving goals."

Some mentees alluded that ongoing communication between the mentor and mentee is key to the success of the program and if this was not the case, the program did not benefit them at all. This was illustrated by both positive and negative comments. On the positive side, mentees wrote "I have my mentor on speed dial" and "when I asked for his assistance with my academics over WhatsApp he assisted me". While the negative aspects were that a few mentees felt that the program did not benefit them due to the lack of communication in the form of face to face meetings or electronic communication. This is what they had to say: "I feel that more work needs to be done in terms of regular meetings" and "Unfortunately, I and my mentor have never met, although when asked a question he did answer. It has not benefit me in a big way."

\section{CONCLUSION}

South African higher education institutions have been grappling with the high dropout rate, specifically at first year level. Despite universities' attempts to implement various strategies to increase student retention, there is very little or no empirical warrant to validate these attempts of research in the South African context. In this study we analysed the characteristics and academic performance of the mentees to gain an understanding of how discipline-specific peer mentoring can influence students' academic performance and hence, contribute to empirical research in the South African context on peer mentoring and its use as a catalyst to enhance first years' academic performance.

The findings revealed that the majority of mentees (75\%) were enrolled for the BCom 4year program and that most of the mentees $(72.2 \%)$ enrolled for Economics for the first time. Given the challenges first year students face to transition from high school to university, it is understandable that such a high number of students registering for Economics for the first time were eager to participate in the programme. Furthermore, students in the extended curriculum 
programme are also aware that they need additional support to cope with the stressful demands presented to them at university, hence the eagerness of students to participate in the programme.

It was interesting to note that the mentees were associated with a significantly higher tutorial attendance as opposed to non-mentees. This factor could be attributed to the weekly motivational messages sent by the mentors and to on-going face-to-face contact sessions between the mentors and mentees which was evident in the surveys. Tinto (1995) found that where students learned from their peers they learned more and persisted at a higher rate than did similar students in more traditional learning settings. Hence, the critical factor here is that while students are expected to follow a particular timetable to complete their degrees, it is also important that they are given the platform to collaborate with their peers in a flexible learning space.

The two most significant findings of this study are that: a) the mean CAM of the mentees (73.6) is significantly higher compared to students who were not mentees and, b) the mentees' final examination performance was also higher (60.9 versus 52.9). These findings correlate with the two objectives of this study. Firstly, we wanted to promote Economics education due to the low enrolment for this subject at second and third year level. Secondly, to achieve the first objective, it was also our vision to increase the pass rate of first year Economics students. Hence, these findings revealed that subject-specific peer mentoring creates a platform for a shared learning experience (Tinto 1995) and more importantly, enhance student success (Johnson 2002; Tinto 1998).

\section{RECOMMENDATIONS}

This study highlights the possibilities of using peer mentoring as a catalyst to enhance first year academic performance. The evidence as revealed in the study provides insights into these possibilities. We argue that senior students can be a great source of contributing to the first year experience and that universities should strongly consider to "tap" into this resource. While this study did not focus on the peer mentor, we also found that they were willing to participate voluntarily in this programme, as they believed that there are benefits to being a peer mentor.

The recommendation for South African universities is to explore the possibilities of implementing subject-specific peer mentoring programmes to improve the academic performance of particularly first year students. Given that this programme was voluntary for both mentors and mentees, very little funding was required. In this way, universities can sustain such programmes without the burden of requiring on-going funding.

Although Du Preez, Steenkamp and Baard's $(2013,1230)$ study revealed several benefits for both mentors and mentees, we argue that the austerity measures South African universities 
are currently experiencing, especially the under resourced universities, would not allow these institutions to remunerate peer mentors, as was the case with the way this current study was conducted. We believe that other means of "remuneration" should be considered to compensate peer mentors. For example, as in the case of our study, peer mentors" "compensation" was the marks allocated to their module for their participation in the program. Hence, the peer mentoring programme should form part of the module. Given that South African higher education is labelled a "low participation, high attrition" system (CHE 2013, 52), peer mentoring should be strongly considered as a standard practice across all universities to retain students and enhance student success without the financial burden. To conclude we concur with Tinto's (2009) notion of student success:

"Student success does not arise by chance. It is the result of an intentional, structured, and proactive set of strategies that are coherent and systematic in nature and carefully aligned to the same goal; second that at no time is a coherent systematic structure more important than in the first year of university studies. Many learning communities do more than co-register students around a topic. They change the manner in which students experience the curriculum and the way they are taught."

\section{NOTE}

1. As part of the programme structure, the mentors were expected to create a WhatsApp group to establish a platform to communicate with students. These mentors were encouraged to use this platform to assist their mentees with any queries related to Economics and give weekly motivational messages. Evidence of these conversations were required to obtain a mark and a certificate of participation. As we stated in the article, this peer mentor programme was embedded in the ECO133 module.

\section{REFERENCES}

Allan, P. 2007. The benefits and impacts of coaching and mentoring programme for teaching staff in secondary school. International Journal of Evidence Based Coaching and Mentoring 5(2): 12-21.

Angelique, H., K. Kyle and E. Taylor. 2002. Mentors and muses: New strategies for academic success. Innovative Higher Education 26: 195-209.

Arendale, D. R. 2007. Post-secondary peer cooperative learning programs: Annotated bibliography. Minneapolis: College of Education and Human Development, University of Minnesota.

CHE see Council of Higher Education

Clark, R., J. Andrews and P. Gorman. 2012/2013. Tackling transition: The value of peer mentoring. Widening Participation and Lifelong Learning 14(1): 57-75.

Crisp, G. and I. Cruz. 2009. Mentoring college students: A critical review of the literature between 1990 and 2007. Research in Higher Education 50(6): 525-545. http://dx.doi.org/10.1007/s11162-0099130-2

Du Preez, R., P. Steenkamp and R. Baard. 2013. An investigation into a peer module mentoring programme in Economic and Management Sciences. International Business \& Economics Research Journal 12(10): 1225-1238

Falchikov, N. 2001. Learning together: Peer tutoring in higher education. New York: Routledge Farmer. 
Fox, A. and L. Stevenson. 2006. Exploring the effectiveness of peer mentoring of accounting and finance students in higher education. Accounting Education 15(2): 189-202.

Hall, R. and Z. Jaugietis. 2010. Developing peer mentoring through evaluation. Innovation Higher Education 36: 41-52. DOI 10.1007/s10755-010-9156-6.

Hamilton, R. 2003. Mentoring: A practical guide to the skills of mentoring. London: Spiro Press.

Higgins, B. 2004. Relationship between retention and peer tutoring for at-risk students. The Journal of Nursing Education 43(7): 319.

Horn, P., A. Jansen and D. Yu. 2011. Factors explaining the academic success of second-year economics students: an exploratory analysis. South African Journal of Economics 79(2): 202-210.

Johnson, W. B. 2002. The intentional mentor: Strategies and guidelines for the practice of mentoring. Professional Psychology: Research and Practice 33: 88-96.

Kieran, P. and G. O'Neill. 2009. Peer-assisted tutoring in a chemical engineering curriculum: Tutee and tutor experiences. Australasian Journal of Peer Learning 2(1): 40-67.

Keup, J. 2016. Peer leadership as an emerging high-impact practice: An exploratory study of the American experience. Journal of Student Affairs in Africa |4(1): 33-52

Kirkham, R. and D. Ringelstein. 2008. Student peer assisted mentoring (SPAM): A conceptual framework. E-Journal of Business Education \& Scholarship of Teaching 2(2): 39-49.

Kram, K. and L. Isabella. 1985. Mentoring alternatives: The role of peer relationships in career development. Academy of Management Journal 28: 110-132.

McLean, M. 2004. Does the curriculum matter in peer mentoring? From mentee to mentor in problembased learning: A unique case study. Mentoring \& Tutoring 12: 173-186.

Mee-Lee, L. and T. Bush. 2003. Student mentoring in higher education. Hong Kong Baptist University, Mentoring \& Tutoring 11: 263-271.

Siegfried, J. J. and R. Fels. 1979. Research on teaching college economics: A survey. Journal of Economic Literature 17(3): 923-969.

Terrion, L. and G. Leonard. 2007. A taxonomy of the characteristics of student peer mentors in higher education: Findings from a literature review. Mentoring \& Tutoring 15(2): 149-164.

Tinto, V. 1993. Leaving college: Rethinking the causes and cures of student attrition. $2^{\text {nd }}$ Edition. Chicago: The University of Chicago Press.

Tinto, V. 1995. Learning communities, collaborative learning, and the pedagogy of educational citizenship. AAHE Bulletin 47(7): 11-13.

Tinto, V. 1998. Colleges as communities: Taking research on student persistence seriously. Review of Higher Education 21: 167-177.

Tinto, V. 2009. Taking student retention seriously: Rethinking the first year of university. Keynote speech delivered at the ALTC FYE Curriculum Design Symposium Queensland University of Technology, Brisbane, Australia, February 5, 2009. 